\title{
Collective levels of stigma and national suicide rates in 25 European countries
}

\author{
G. Schomerus ${ }^{1,2 *}$ †, S. Evans-Lacko ${ }^{3,}$ †, N. Rüsch ${ }^{4}$, R. Mojtabai ${ }^{5}$, M. C. Angermeyer ${ }^{6,7}$ and \\ G. Thornicroft ${ }^{3}$ \\ ${ }^{1}$ Department of Psychiatry, Greifswald University, Greifswald, Germany \\ ${ }^{2}$ HELIOS Hanseklinikum Stralsund, Stralsund, Germany \\ ${ }^{3}$ Health Service and Population Research Department, King's College London, Institute of Psychiatry, London, UK \\ ${ }^{4}$ Department of Psychiatry II, University of Ulm, Ulm, Germany \\ ${ }^{5}$ Department of Mental Health, Johns Hopkins Bloomberg School of Public Health, Baltimore, Maryland, USA \\ ${ }^{6}$ Department of Public Health, University of Cagliari, Cagliari, Italy \\ ${ }^{7}$ Center for Public Mental Health, Gösing am Wagram, Austria
}

\begin{abstract}
Aims. There is substantial diversity in national suicide rates, which has mainly been related to socio-economic factors, as well as cultural factors. Stigma is a cultural phenomenon, determining the level of social acceptance or rejection of persons with mental illness in a society. In this study, we explore whether national suicide rates are related to the degree of mental illness stigma in that country.
\end{abstract}

Methods. We combine the data on country-level social acceptance (Eurobarometer) with the data on suicide rates and socio-economic indicators (Eurostat) for 25 European countries.

Results. In a linear regression model controlling for socio-economic indicators, the social acceptance of someone with a significant mental health problem in 2010 was negatively correlated with age standardised national suicide rates in the same year $(\beta-0.46, p=0.014)$. This association also held true when combining national suicide rates with death rates due to events of undetermined intent.

Conclusions. Stigma towards persons with mental health problems may contribute to differences in suicide rates in a country. We hypothesise possible mechanisms explaining this link, including stigma as a stressor and social isolation as a consequence of stigma.

Received 22 November 2013; Revised 14 January 2014; Accepted 18 January 2014; First published online 27 February 2014

Key words: Economic crisis, Eurobarometer, social distance, suicide.

\section{Introduction}

There is a substantial variation in national suicide rates, which has been attributed to socio-economic factors (Lorant et al. 2005; Stuckler et al. 2009; Yur'yev et al. 2013) and genetic predispositions (Marušič \& Farmer, 2001), as well as to religious or cultural influences that vary between countries (Knox et al. 2004). So far, a few studies have investigated the relationship between the population attitude and the suicide rates, examining for example the permissive attitude towards suicide in a country with higher suicide rates (Stack \& Kposowa, 2008). A recent comparative study of two neighbouring European regions (Flanders and The

\footnotetext{
† Both authors contributed equally to this work.

* Address for correspondence: Dr G. Schomerus, Department of Psychiatry, University of Greifswald, Rostocker Chaussee 70, 17437 Stralsund, Germany.

(Email: georg.schomerus@uni-greifswald.de)
}

Netherlands) showed more self-stigma, shame and negative attitude towards help-seeking in Flanders, the region with considerably higher suicide rates (Reynders et al. in press). This finding raises the question whether mental illness stigma could play a role in explaining differences in suicide rates across several countries. Mental illness stigma has been shown to reduce the perceived need for help (Schomerus et al. 2012), impair adherence to treatment (Sirey et al. 2001), decrease self-esteem and hope (Corrigan et al. 2011) and increase social isolation and withdrawal (Link et al. 1997; Angermeyer et al. 2004; Thornicroft et al. 2009; Lasalvia et al. 2013) - factors that could contribute to higher suicide rates.

Stigma is a collective phenomenon, mirroring the cultural significance of having mental illness in a society. Recent cross-national studies link variations in population levels of stigma to individual outcomes such as self-stigma, help-seeking preferences or unemployment (Mojtabai, 2010; Evans-Lacko et al. 
2012 , 2013), demonstrating that the degree of stigma in a country has implications for the way mental illness is experienced in that country.

In this study, we examine the relationship between the desire for social distance from persons with mental illness and the national suicide rates. Specifically, we use the percentage of respondents in a country stating that they are comfortable talking to a person with mental health problems as an indicator of a low desire for social distance, or of social acceptance. We hypothesise that higher levels of social acceptance are associated with lower suicide rates, even after controlling known socio-economic predictors of suicide.

\section{Methods}

\section{Eurobarometer survey}

We examined the data on the prevalence of stigma in a country from the Eurobarometer survey 2010 (European Union, 2010). Eurobarometer survey data were collected via face-to-face interviews among European Union citizens ( $n=26800$ in 2010, approximately 1000 individuals per country per year). Multi-stage random (probability) sampling was used in each country. For our analysis, we included all 25 countries which also had data on suicide rates as compiled by Eurostat (European Commission, 2013): Greece, Cyprus, Italy, Spain, Malta, United Kingdom, Netherlands, Sweden, Bulgaria, Germany, Luxembourg, Romania, Ireland, France, Austria, Portugal, Czech Republic, Slovenia, Finland, Slovakia, Estonia, Poland, Hungary, Latvia, Lithuania.

As an indicator of public stigma, we used an item on social distance from persons with mental health problems from the Eurobarometer 2010 survey. The item asks individuals: 'Which of the following two statements best describe how you feel: (1) You would find it difficult talking to someone with a significant mental health problem? or (2) You would have no problem talking to someone with a significant mental health problem?' Respondents were required to select either statement (1) or (2), a third answer possibility was '(3) don't know'. Those who endorsed the second statement were categorised as feeling comfortable talking to someone with a mental health problem, indicating a low desire for social distance. For reasons of simplicity, we use the term 'social acceptance' instead of 'low desire for social distance'. Using population weights for each country, the country level of social acceptance was computed as a weighted average (\%).

\section{Socio-economic indicators}

Several studies have linked worsening economic conditions such as higher unemployment rates and lower gross domestic product (GDP) to higher suicide rates (Lundin et al. 2012; Wahlbeck \& McDaid, 2012; Yur'yev et al. 2013). Widening economic inequalities may increase exclusion of vulnerable groups and has also been linked to increased suicide rates (Hong et al. 2011). As potential country-level socio-economic determinants of suicide rates, we thus investigated three socio-economic indicators in 2010: national unemployment rate (in \% of the labour force), the Gini-index as an indicator of inequality (range, 0-1, higher values indicate greater inequality) and decline of the GDP per capita since 2008 (in \%, reflecting the economic consequences of the economic crisis) (European Commission, 2013).

\section{Suicide rates}

National suicide rates for 2010 were taken from the Eurostat database (European Commission, 2013). The figures represent the age standardised death rate per 100000 people from suicide and intentional self-harm (ICD-10 codes X60-X84, Y87.0). Although the reporting of deaths by suicide follows different procedures in each country, it is generally agreed that these differences do not introduce a systematic bias (Stuckler et al. 2009). To account for potential differences in under-reporting suicides in a country, however, we repeated our analyses including deaths due to 'events of undetermined intent', which is commonly assumed to contain a certain proportion of undetected suicides (Värnik et al. 2012). We thus generated a new variable with a combined rate of suicides and undetermined deaths for each country. Suicide rates and combined death rates did correlate highly $(r=0.93, p<0.001)$.

\section{Statistical analysis}

We used a stepwise approach to determine the relationship between country-level stigma and suicide rates. First, we examined pairwise correlations between all variables. Second, we performed a series of linear regression analyses with suicide rates as the dependent variable, entering country-level stigma first and then adding the economic indicators. Examination of a scatter-plot relating suicide rates to stigma prevalence showed particularly high suicide rates and stigma for Lithuania. To reduce the impact of this outlier, we excluded Lithuania from our final model. All analyses were conducted with STATA, version 12.1 (StataCorp, 2011).

\section{Results}

Table 1 shows pairwise correlations between suicide rates, stigma and economic indicators. Higher suicide 
Table 1. Pairwise correlation of country-level suicide rate, stigma, economic indicators and country-level psychological distress in 25 European countries in 2010

\begin{tabular}{lcllll}
\hline & $\begin{array}{c}\text { Suicide rate } \\
2010\end{array}$ & $\begin{array}{c}\text { Comfortable talking to } \\
\text { a person with MHP }\end{array}$ & $\begin{array}{c}\text { GDP decline } \\
2008-2010(\%)\end{array}$ & $\begin{array}{c}\text { Gini } \\
2010\end{array}$ & $\begin{array}{c}\text { Unemployment } \\
\text { rate } 2010\end{array}$ \\
\hline $\begin{array}{l}\text { Comfortable talking to a } \\
\text { person with MHP }\end{array}$ & $-0.40^{*}$ & 1.00 & & \\
GDP decline 2008-2010 (\%) & $0.44^{*}$ & -0.30 & 1.00 & 1.00 \\
Gini 2010 & -0.02 & $-0.59^{* *}$ & $0.45^{*}$ & $0.57^{* *}$ & 1.00 \\
Unemployment rate 2010 & 0.31 & $-0.39^{*}$ & $0.60^{* * *}$ \\
\hline
\end{tabular}

Note: MHP, mental health problems; GDP, gross domestic product.

${ }^{*} p<0.05,{ }^{* *} p<0.01$ and ${ }^{* * *} p<0.001$.

Table 2. Aggregate predictors of national suicide rates in 2010. Linear regression analysis; standardised coefficients ( $\beta$ )

\begin{tabular}{|c|c|c|c|c|c|c|}
\hline \multirow[b]{2}{*}{ National suicide rate in 2010} & \multicolumn{2}{|c|}{$\begin{array}{c}\text { Model } 1 \\
(n=25)\end{array}$} & \multicolumn{2}{|c|}{$\begin{array}{c}\text { Model } 2 \\
(n=25)\end{array}$} & \multicolumn{2}{|c|}{$\begin{array}{c}\text { Model } 3 \\
\text { (without Lithuania, } \\
n=24 \text { ) }\end{array}$} \\
\hline & $\beta$ & $p$ & $\beta$ & $p$ & $\beta$ & $p$ \\
\hline Comfortable talking to a person with MHP & -0.40 & 0.047 & -0.61 & 0.004 & -0.46 & 0.014 \\
\hline GDP decline 2008-2010 & & & 0.48 & 0.019 & 0.53 & 0.007 \\
\hline Gini 2010 & & & -0.74 & 0.003 & -0.89 & $<0.001$ \\
\hline Unemployment rate 2010 & & & 0.25 & 0.242 & 0.20 & 0.301 \\
\hline Adjusted $R^{2}$ & 0.12 & & 0.45 & & 0.50 & \\
\hline
\end{tabular}

Note: MHP, mental health problems; GDP, gross domestic product per capita.

rates significantly correlated with lower social acceptance of persons with mental illness and with GDP decline between 2008 and 2010. Economic indicators showed the expected inter-correlations: greater decline in GDP was correlated with higher inequality and higher unemployment rates, and greater levels of inequality were correlated with higher unemployment rates.

Table 2 shows the results of our regression analyses. The negative relationship between national suicide rates and country-level social acceptance of persons with MHP persisted when economic indicators were entered into the equation, resulting in a standardised coefficient of $-0.46(p=0.014)$ in the final model (excluding Lithuania). This model explained $50 \%$ of the variance of national suicide rates (Table 2). Repeating these analyses with combined rates of suicide and undetermined death as the dependent variable yielded similar results: comfortably talking to persons with MHP was negatively related to the combined death rate (all 25 countries: $\beta=-0.62, p=0.004$; excluding Lithuania: $\beta=-0.51, p=0.011$, adjusted R2: 44 and $42 \%$, respectively).

\section{Discussion}

We found a significant inverse relationship between national suicide rates and social acceptance of persons with mental health problems in a cross-sectional analysis using country-level data from 25 European countries. This relationship also held true when including rates of undetermined deaths per country. This is the first study linking national levels of stigma towards persons with mental illness to national suicide rates, lending support to the hypothesis that stigma is associated with higher prevalence of suicide. Before discussing hypotheses on potential mechanisms behind this link, however, it is important to consider the limitations of this study.

\section{Limitations}

Looking at stigma and suicide rates as collective phenomena, we used cross-sectional, aggregate-level data as both dependent and independent variables. Our results thus cannot prove that there is a relationship between country-level stigma and individual suicidal behaviour ('ecological fallacy'), but rather 
encourage further research following this hypothesis. We did not examine the role of individual risk factors for suicidal behaviour nor individual reactions to stigma. Previous studies combining individual-level data on stigma experience and country levels of stigma have, however, shown that aggregate stigma levels have a negative impact on individual experiences of mental illness (Mojtabai, 2010; Evans-Lacko et al. 2012, 2013). The role of stigma in individual suicidal behaviour has only just started to be examined, and, for pragmatic reasons, has been restricted to retrospective analyses of attempted suicides (Bruffaerts et al. 2011). Although suicide rates across Europe have been regarded as a relatively unbiased outcome measure (Stuckler et al. 2009), we accounted for potential differences in suicide recording in a country by repeating our analyses including deaths of undetermined intent. Nevertheless, the validity of our single-item stigma indicator could be questioned. Its relation to individual stigma experience in multilevel analysis (Evans-Lacko et al. 2012) however indicates that it is indeed reflective of the degree of openness towards persons with mental illness in a country. It is a particular strength of this study that prevalence of stigma within countries was elicited using large nationally representative samples of approximately 1000 respondents per country.

As in all cross-sectional studies, we cannot exclude the possibility that 'reverse causality' contributed at least in part to the observed relationships. Theoretically, highsuicide rates could frame negative public attitudes towards mental health problems, because more persons have negative, suicide-related experiences with mental illness. In contrast to this assumption, however, a recent study in Australia found that exposure to suicide was associated with better suicide literacy, and was unrelated to stigmatising attitudes (Batterham et al. 2013). In their study, Batterham and co-workers investigated the stigma of suicide rather than the stigma of mental illness, and future research is warranted to explore potential differences between these two types of stigma and their influence on suicide rates. Finally, our study included European countries only. Investigation of a possible relationship between stigma and suicide in more diverse geographical regions and using different study designs is warranted.

\section{Potential mechanisms linking stigma to suicide rates}

Being aware that this ecological study does not permit conclusions about the relationship between the experience of stigma and suicide on an individual level, we hypothesise three mechanisms of how stigma could potentially increase the suicide rates. First, according to the stress-diathesis model of suicidal behaviour, psychosocial stressors can increase the suicidality
(Van Heeringen, 2012). Stress-coping models of stigma frame stigma as a social stressor that in turn can lead to negative emotional reactions, social withdrawal and hopelessness among people with mental illness, especially if the perceived threat of stigma and social rejection exceeds the coping resources of the individual (Rüsch et al. 2009).

Second, stigma contributes to the social isolation of a person experiencing a severe mental health problem (Link et al. 1989). Social isolation has long been recognised as a risk factor for suicide (Trout, 1980). The item on comfort/reluctance in talking to a person with a mental health problem used in this study directly addresses social isolation of affected persons. Barriers to discussing one's mental health status can have particularly serious consequences in a person considering suicide. A more open cultural climate regarding psychological and emotional health problems likely facilitates self-disclosure and help-seeking and could thus prevent suicides, which is in line with the recent findings comparing attitudes towards help-seeking and stigma in a low- and a high-suicide region in Europe (Reynders et al. in press).

Third, collective levels of stigma are predictive of individual stigmatising attitudes in a population (Mojtabai, 2010) and of individual self-stigma (EvansLacko et al. 2012). Studies on predictors of help-seeking have shown that both individual stigmatizsing attitudes and self-stigma are associated with lower willingness to seek help for mental health problems (Vogel et al. 2006; Schomerus et al. 2009), which could, in turn, increase the individual risk for suicide. Studies combining data on collective levels of stigma and individual level attitudes, help-seeking and suicidal behaviour are needed to establish this hypothetical link.

Of note, we observed significant correlations between social acceptance of persons with mental illness and population level economic distress as measured by GDP decline and a high Gini-index. Higher levels of stigma thus seem to be partly reflective of the level of economic stress in a country (Angermeyer et al. 2013).

In conclusion, this study found that country-level stigma surrounding mental illness is related to national suicide rates. More research is needed to establish a link between stigma and suicidal risk at the individual level and to investigate and test potential causal mechanisms. Suicide prevention initiatives should address population-level attitudes and reactions to people with mental illness.

\section{Financial Support}

This research received no specific grant from any funding agency, commercial or not-for-profit sectors. 


\section{Conflict of Interest}

SEL and RM report personal fees from Lundbeck Pharmaceuticals, outside the submitted work. The other authors declare that they have no conflicts of interest.

\section{Ethical Standard}

The authors assert that all procedures contributing to this work comply with the ethical standards of the relevant national and institutional committees on human experimentation and with the Helsinki Declaration of 1975, as revised in 2008.

\section{References}

Angermeyer MC, Beck M, Dietrich S, Holzinger A (2004). The stigma of mental illness: patients' anticipations and experiences. International Journal of Social Psychiatry 50, 153-162.

Angermeyer MC, Matschinger H, Schomerus G (2013). Public attitudes towards people with depression in times of uncertainty: results from three population surveys in Germany. Social Psychiatry and Psychiatric Epidemiology 48, 1513-1518.

Batterham PJ, Calear AL, Christensen H (2013). Correlates of suicide stigma and suicide literacy in the community. Suicide and Life-Threatening Behavior 43, 406-417.

Bruffaerts R, Demyttenaere K, Hwang I, Chiu W-T, Sampson N, Kessler RC, Alonso J, Borges G, De Girolamo G, De Graaf R, Florescu S, Gureje O, Hu C, Karam EG, Kawakami N, Kostyuchenko S, Kovess-Masfety V, Lee $\mathrm{S}$, Levinson D, Matschinger $\mathrm{H}_{\text {, }}$ Posada-Villa J, Sagar R, Scott KM, Stein DJ, Tomov T, Viana MC, Nock MK (2011). Treatment of suicidal people around the world. British Journal of Psychiatry 199, 64-70.

Corrigan PW, Rafacz J, Rüsch N (2011). Examining a progressive model of self-stigma and its impact on people with serious mental illness. Psychiatry Research 189, 339-343.

European Commission, Eurostat (2013). Retrieved 2 July 2013 from http://epp.eurostat.ec.europa.eu/statistics_explained/ index.php/Main_Page.

European Union (2010). Mental Health: Special Eurobarometer 345/Wave 73.2. Retrieved 2 July 2013 from http://ec.europa. eu/health/mental_health/docs/ebs_345_en.pdf.

Evans-Lacko S, Brohan E, Mojtabai R, Thornicroft G (2012). Association between public views of mental illness and self-stigma among individuals with mental illness in 14 European countries. Psychological Medicine 42, 1741-1752.

Evans-Lacko S, Knapp M, Mccrone P, Thornicroft G, Mojtabai R (2013). The mental health consequences of the recession: economic hardship and employment of people with mental health problems in 27 European countries. PloS ONE 8, e69792.
Hong J, Knapp M, Mcguire A (2011). Income-related inequalities in the prevalence of depression and suicidal behaviour: a 10-year trend following economic crisis. World Psychiatry 10, 40.

Knox KL, Conwell Y, Caine ED (2004). If suicide is a public health problem, what are we doing to prevent it? American Journal of Public Health 94, 37-45.

Lasalvia A, Zoppei S, Van Bortel T, Bonetto C, Cristofalo D, Wahlbeck K, Bacle SV, Van Audenhove C, Van Weeghel J, Reneses B, Germanavicius A, Economou M, Lanfredi M, Ando S, Sartorius N, Lopez-Ibor JJ, Thornicroft G (2013). Global pattern of experienced and anticipated discrimination reported by people with major depressive disorder: a cross-sectional survey. Lancet 381, 55-62.

Link BG, Cullen FT, Struening E, Shrout PE, Dohrenwend BP (1989). A modified labeling theory approach to mental disorders: an empirical assessment. American Sociological Review 54, 400-423.

Link BG, Struening EL, Rahav M, Phelan JC, Nuttbrock L (1997). On stigma and its consequences: evidence from a longitudinal study of men with dual diagnoses of mental illness and substance abuse. Journal of Health and Social Behavior 38, 177-190.

Lorant V, Kunst AE, Huisman M, Costa G, Mackenbach J (2005). Socio-economic inequalities in suicide: a European comparative study. British Journal of Psychiatry 187, 49-54.

Lundin A, Lundberg I, Allebeck P, Hemmingsson T (2012). Unemployment and suicide in the Stockholm population: a register-based study on 771,068 men and women. Public Health 126, 371-377.

Marušič A, Farmer A (2001). Genetic risk factors as possible causes of the variation in European suicide rates. British Journal of Psychiatry 179, 194-196.

Mojtabai R (2010). Mental illness stigma and willingness to seek mental health care in the European Union. Social Psychiatry and Psychiatric Epidemiology 45, 705-712.

Reynders A, Kerkhof AJ, Molenberghs G, Van Audenhove C (in press). Attitudes and stigma in relation to help-seeking intentions for psychological problems in low and high suicide rate regions. Social Psychiatry and Psychiatric Epidemiology 49, 231-239.

Rüsch N, Corrigan PW, Powell K, Rajah A, Olschewski M, Wilkniss S, Batia K (2009). A stress-coping model of mental illness stigma: II. Emotional stress responses, coping behavior and outcome. Schizophrenia Research 110, 65-71.

Schomerus G, Matschinger H, Angermeyer MC (2009). The stigma of psychiatric treatment and help-seeking intentions for depression. European Archives of Psychiatry and Clinical Neuroscience 259, 298-306.

Schomerus G, Auer C, Rhode D, Luppa M, Freyberger HJ, Schmidt S (2012). Personal stigma, problem appraisal and perceived need for professional help in currently untreated depressed persons. Journal of Affective Disorders 139, 94-97.

Sirey JA, Bruce ML, Alexopoulos GS, Perlick DA, Raue P, Friedmann SJ, Meyers BS (2001). Perceived stigma as a predictor of treatment discontinuation in young and older outpatients with depression. American Journal of Psychiatry 158, 479-481. 
Stack S, Kposowa AJ (2008). The association of suicide rates with individual - level suicide attitudes: a cross-national analysis. Social Science Quarterly 89, 39-59.

Stuckler D, Basu S, Suhrcke M, Coutts A, Mckee M (2009). The public health effect of economic crises and alternative policy responses in Europe: an empirical analysis. Lancet 374, 315-323.

Thornicroft G, Brohan E, Rose D, Sartorius N, Leese M (2009). Global pattern of experienced and anticipated discrimination against people with schizophrenia: a cross-sectional survey. Lancet 373, 408-415.

Trout DL (1980). The role of social isolation in suicide. Suicide and Life-Threatening Behavior 10, 10-23.

Van Heeringen K (2012). Stress-diathesis model of suicidal behavior. In The Neurobiological Basis of Suicide (ed. Y. Dwivedi). CRC Press: Boca Raton, FL, pp. 113-123.
Värnik P, Sisask M, Värnik A, Arensman E, Van Audenhove C, Van Der Feltz-Cornelis CM, Hegerl U (2012). Validity of suicide statistics in Europe in relation to undetermined deaths: developing the 2-20 benchmark. Injury Prevention 18, 321-325.

Vogel DL, Wade NG, Haake S (2006). Measuring the self-stigma associated with seeking psychological help. Journal of Counseling Psychology 53, 325-337.

Wahlbeck K, Mcdaid D (2012). Actions to alleviate the mental health impact of the economic crisis. World Psychiatry 11, 139-145.

Yur'yev A, Varnik P, Sisask M, Leppik L, Lumiste K, Varnik A (2013). Some aspects of social exclusion: do they influence suicide mortality? International Journal of Social Psychiatry 59, 232-238. 